\title{
Article \\ Deformation Analysis of the Rock Surrounding a Tunnel Excavated through a Gently Dipping Bed
}

\author{
Zhen Gao *D, Jianjun Luo, Xu Wu and Ke Li
}

check for

updates

Citation: Gao, Z.; Luo, J.; Wu, X.; Li, K. Deformation Analysis of the Rock Surrounding a Tunnel Excavated through a Gently Dipping Bed. Appl. Sci. 2022, 12, 1960. https://doi.org/ 10.3390/app12041960

Academic Editor: Fabrizio Balsamo

Received: 14 January 2022

Accepted: 8 February 2022

Published: 13 February 2022

Publisher's Note: MDPI stays neutral with regard to jurisdictional claims in published maps and institutional affiliations.

Copyright: (C) 2022 by the authors. Licensee MDPI, Basel, Switzerland. This article is an open access article distributed under the terms and conditions of the Creative Commons Attribution (CC BY) license (https:// creativecommons.org/licenses/by/ $4.0 /)$.
Key Laboratory for Urban Underground Engineering of Ministry of Education, Beijing Jiaotong University, Beijing 100044, China; jjluo@bjtu.edu.cn (J.L.); wu-xu@bjtu.edu.cn (X.W.); 20125891@bjtu.eud.cn (K.L.)

* Correspondence: 17115299@bjtu.edu.cn; Tel.: +86-159-0105-9417

\begin{abstract}
To investigate the deformation and stability of the rock surrounding a tunnel excavated through layered rock, a three-dimensional numerical simulation was conducted to compare and analyze the right line of the YD2K100+560-630 two-stage docking cross-section of the Yuelongmen Tunnel using a ubiquitous joint model. Based on 3-D numerical simulations, the following conclusions were drawn: (1) The excavation on the construction entrance side significantly disturbed the construction exit side, and the exit side was more disturbed in the steeply dipping layer than in the gently dipping layer. (2) The influence of the dip angle of the laminae on the uplift of the tunnel invert was greater than the influence on the tunnel vault settlement when the laminae were oriented perpendicular to the trend of the tunnel and two-stage docking excavation was used. (3) When two-stage excavation was applied to gently inclined laminated rock, there was an obvious disturbance to both the top of the tunnel (less than one time the diameter of the through face; and to the bottom of the tunnel within 0.5 time the diameter of the through face on the side with the stopping construction exit side during the tunnelling process. When tunnel excavation was conducted against the trend of the layer, there was obvious disturbance to the top of the tunnel within 0.5 time the diameter of the through face and to the bottom of the tunnel within one time the diameter of the entrance face) on the construction exit side during the tunnelling process due to the presence of laminae. The excavation on the construction entrance side significantly disturbed the construction exit side. When docking and penetrating layered rock tunnels, priority should be given to docking and penetrating in the direction corresponding to the layers, and temporary support on the exit side should be strengthened to ensure the deformation stability of the surrounding rock mass.
\end{abstract}

Keywords: long tunnels; bedding plane; ubiquitous joint model; tunnel through

\section{Introduction}

In the construction of transportation networks in southwestern China, there are increased cases of tunnel construction through foliated rock, such as the Daliangmeng tunnel of the Wuqi Expressway [1], the Muzhailing tunnel of the Lan-Yu Railway [2], and the Yangjiaping tunnel [3]. Unlike isotropic surrounding rock masses, the deformation and strength of foliated surrounding rock masses display obvious anisotropy. Due to problems related to the deformation and stability of foliated surrounding rock masses encountered in engineering, the concept of anisotropy has gradually entered the vision of scholars and has been studied in depth [4-6]. The anisotropic properties of foliated surrounding rock masses, i.e., strength and deformation, have a great impact on the deformation and damage characteristics of the surrounding rock masses. Usually, when tunneling under foliated surrounding rock masses, the deformation of the surrounding rock masses exhibits obvious asymmetry. In addition, when the dip angle of the bedding plane is less than $30^{\circ}$, both the top and bottom of the tunnel are prone to damage. In the past, the tunnel span of the railroad industry was relatively small, and the engineering properties of the gently inclined rock layer did not attract sufficient attention. However, with the increase in tunnel 
construction under the complex geological conditions of southwestern China, the technical problems encountered in construction involving a gently inclined rock layer have gradually received more attention [7-9]. In addition, with the increase in the number of long tunnels, to achieve tunnel penetration as soon as possible, it is often necessary to use inclined shafts or horizontal adits to increase the auxiliary working face for tunnel construction, which shortens the construction period. Compared with inclined shafts, horizontal adits have lower environmental requirements and are widely used in certain geological environments, such as those with large burial depths and high ground stresses; thus, it is becoming more common to use horizontal adits to increase the auxiliary working faces during tunnel penetration [10]. However, the simultaneous construction of two excavation working faces leads to superposition of the disturbance area, which has a serious impact on the stability of the tunnel and is more dangerous than one-way tunneling. For foliated surrounding rock, due to the weak plane of the gently inclined rock, it is more difficult to control the stability of the surrounding rock. If the excavation method is not appropriate or the support design is not reasonable, it can easily cause tunnel collapse, delay in the construction schedule, increased project input, and safety problems. Therefore, the selection of the tunnel penetration working face is a key point in the construction of a tunnel through gently inclined, foliated surrounding rock.

In this study, the deformation caused by the excavation of the two-stage cross-section of the Yuelongmen Tunnel of the Chengdu-Lanzhou Railway in southwestern China was compared with the deformation results of the FLAC3D numerical simulation. Based on this, the deformation caused by tunnel excavation through gently inclined rock was analyzed to provide a reference for the selection of reasonable construction methods.

\section{Project Overview}

The Yuelongmen Tunnel is located in the area between Gaochuan (Gaochuan Station) and Mao County (Mao County Station) in Mianyang. It is a two-lane tunnel with double excavation of the left and right tunnels and a line spacing of $29.999-62.493 \mathrm{~m}$. We took the YD2K100+560-630 section of the Yuelongmen Tunnel as our research object. The excavation of this section revealed that the surrounding rocks are phyllite, carbonaceous shale, and limestone, among which carbonate rocks, such as the limestone, are interbedded. The overall appearance is gray-black, gray, and gray-white, with thin laminae, plates, and sheet structures, and localized medium-thick layers. The laminated fissures are more developed. A schematic diagram of the excavation of the YD2K100+560-YD2K100+630 section of the right line of the tunnel is shown in Figure 1.

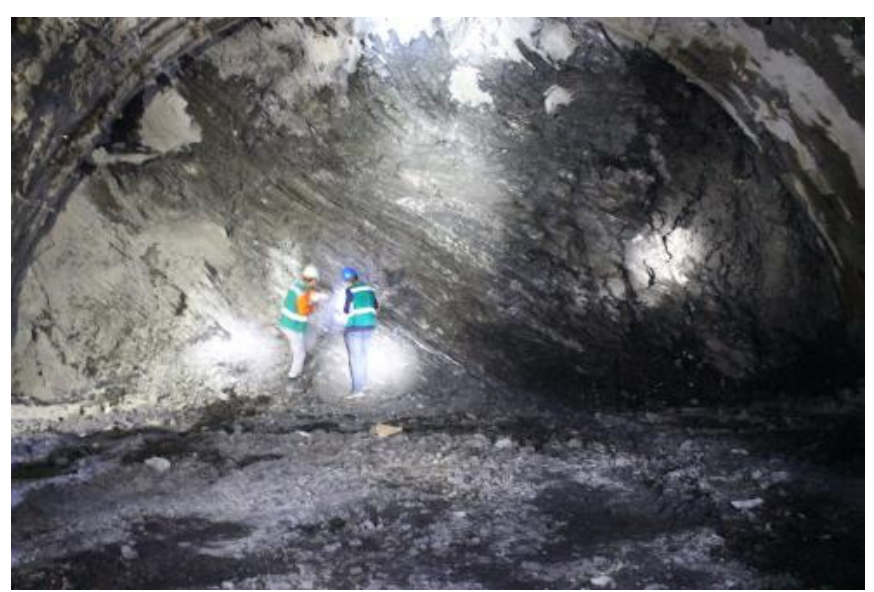

(a)

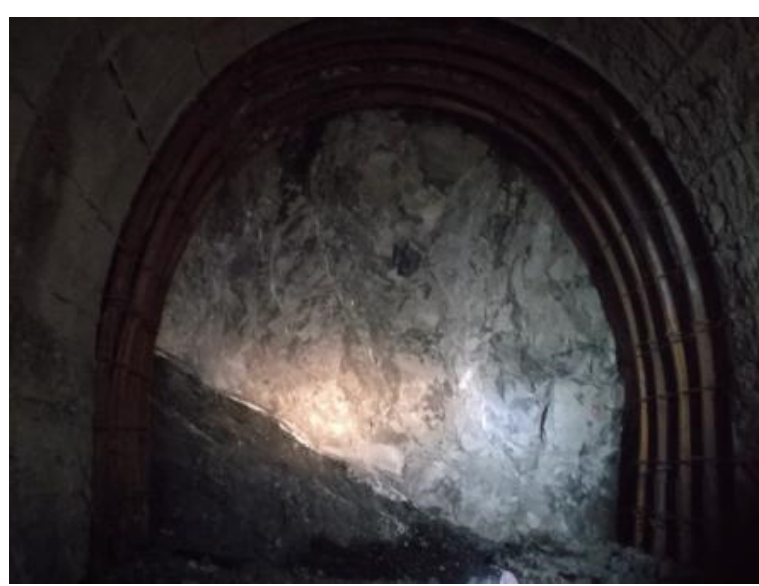

(b)

Figure 1. Diagram of the rock around the excavation of the right line of the Yuelongmen Tunnel for section YD2K100+560-630: (a) tunnel section YD2K100+565; (b) tunnel section YD2K100+610. 
The tunnel is located in the Longmen Mountain tectonic zone, which is a pushovertype tectonic zone. The overall orientation of the tectonic zone is $45^{\circ}$ northeast, with a total length of about $500 \mathrm{~km}$ and a width of $25-50 \mathrm{~km}$. There are three main east-westtrending fractures in the tectonic zone: the Longmen Front Range Fault, the Longmen Mountain Main Central Fault, and the Longmen Back Range Fault. The tectonic movement started in the northwest direction and increased toward the southeast, producing a total of three successive stacked-tile-recoil zones [11]. As a result, the tectonic zone is generally characterized by descending steps from northwest to southeast, with a height difference of about $600-700 \mathrm{~m}$ at each end. The longitudinal section of the tunnel is shown in Figure 2.

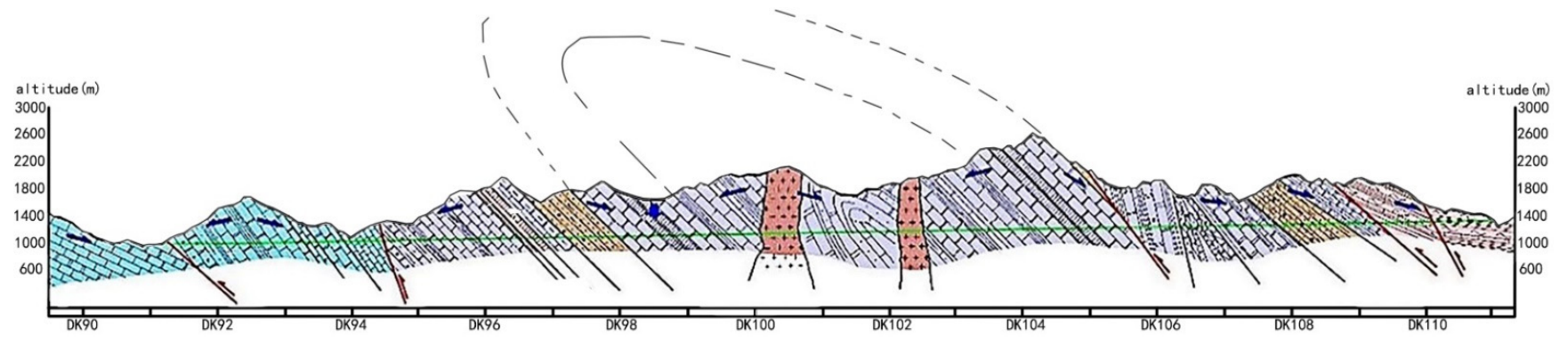

Figure 2. Vertical section of the Yuelongmen Tunnel.

The field ground stress test was conducted using a hydraulic fracturing technique [12], and the measured joints were calculated and organized to obtain the distribution of the ground stress in the area that the tunnel crosses. The maximum horizontal principal stress was $20-25 \mathrm{MPa}$, the direction of the maximum horizontal principal stress was predominantly $\mathrm{NE}$, and the average maximum horizontal principal stress direction was $\mathrm{N} 31^{\circ} \mathrm{E}$ based on the test results. The burial depth of this section is about $1000 \mathrm{~m}$, and the vertical stress is about $27 \mathrm{MPa}$. According to the test results, the regional stress field type was preliminarily classified as $\sigma_{\mathrm{v}}>\sigma_{\mathrm{H}}>\sigma_{\mathrm{h}}$.

\section{Numerical Model and Physical-Mechanical Parameters}

\subsection{Ubiquitous Joint Model}

For numerical simulation analysis of layered rock masses, most scholars have used a ubiquitous joint model [10-14] for the analysis and investigation of tunneling, as well as slope and mining engineering applications. This model is based on the Mohr-Coulomb model with the addition of weak planes to simulate the existence of joints, which also obeys the Mohr-Coulomb yield strength criterion [15]. A schematic diagram of the material in the ubiquitous joint model is shown in Figure 3. The parameters of the joint face include the cohesion, the dilation, the friction, and the tension. The model considers both the physical and mechanical properties of the rock matrix and the joints. The rock damage is divided into three components: rock matrix damage, joint face damage, and both, depending on factors such as the rock's stress state, joint production, and the mechanical properties of the rock and joints. The elastic law and yield criterion followed by the weak planes are shown in Sections 3.1.1 and 3.1.2.

\subsubsection{Elasticity}

For the orientation of the weak plane (i.e., the joint), the normal vector of the weak plane in the Cartesian coordinate system is represented by global coordinates $\mathrm{x}, \mathrm{y}$, and $\mathrm{z}$ (Figure 4). In the local coordinate system, $\mathrm{x}^{\prime}$ is the direction of the weak plane, $\mathrm{y}^{\prime}$ is the tendency of the weak plane, and $z^{\prime}$ is the normal direction of the weak plane. 
element

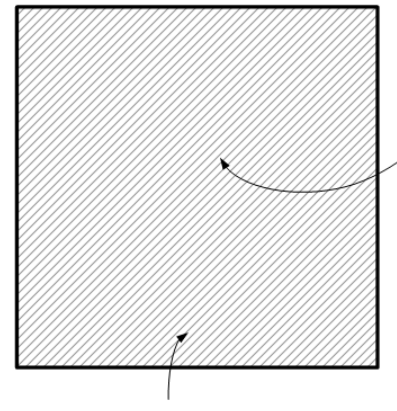

elastoplastic solid matrix

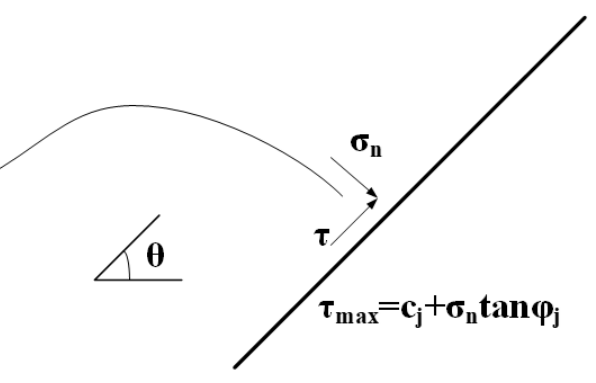

weak plane

Figure 3. Schematic diagram of the ubiquitous joint model material.

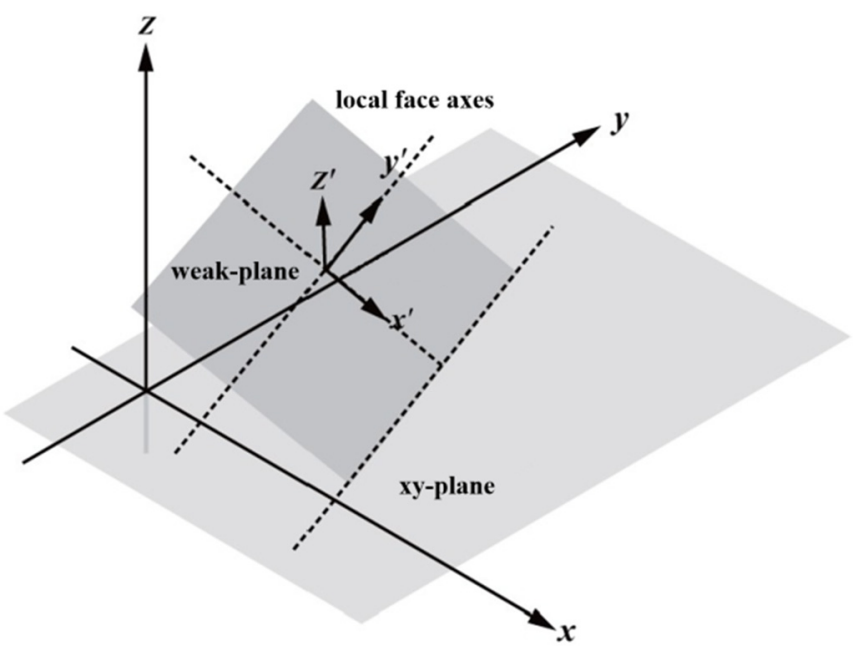

Figure 4. The relationship between the global coordinate system and the local coordinate system of the joint plane.

The relationship between the stresses, in general, and the local coordinates is expressed as follows:

$$
[\sigma]^{\prime}=[C]^{T}[\sigma][C]
$$

where $[C]^{T}$ denotes the transpose of a matrix of $[C]$, which represents the rotation tensor of the cosine of the $x^{\prime}, y^{\prime}$, and $z^{\prime}$ directions:

$$
[C]=\left[\begin{array}{lll}
\cos \left(x^{\prime}, x\right) & \cos \left(x^{\prime}, y\right) & \cos \left(x^{\prime}, z\right) \\
\cos \left(y^{\prime}, x\right) & \cos \left(y^{\prime}, y\right) & \cos \left(y^{\prime}, z\right) \\
\cos \left(z^{\prime}, x\right) & \cos \left(z^{\prime}, y\right) & \cos \left(z^{\prime}, z\right)
\end{array}\right]
$$

where the spread over the nodal model, the generalized stress tensor describing the damage to the weak plane, is described as $\sigma_{1^{\prime} 1^{\prime}}, \sigma_{2^{\prime} 2^{\prime}}, \sigma_{3^{\prime} 3^{\prime}}$, and $\Delta \tau$, and the corresponding strain tensor is shown as $\varepsilon_{1^{\prime} 1^{\prime}}, \varepsilon_{2^{\prime} 2^{\prime}}, \varepsilon_{3^{\prime} 3^{\prime}}$, and $\Delta \gamma$. The incremental expression of Hooke's law [16] corresponding to the weak plane is:

$$
\begin{aligned}
& \left\{\begin{array}{l}
\Delta \sigma_{1^{\prime} 1^{\prime}}=\alpha_{1} \Delta \varepsilon_{1^{\prime} 1^{\prime}}^{e}+\alpha_{2}\left(\Delta \varepsilon_{2^{\prime} 2^{\prime}}^{e}+\Delta \varepsilon_{3^{\prime} 3^{\prime}}^{e}\right) \\
\Delta \sigma_{2^{\prime} 2^{\prime}}^{e}=\alpha_{1} \Delta \varepsilon_{2^{\prime} 2^{\prime}}^{e}+\alpha_{2}\left(\Delta \varepsilon_{1^{\prime} 1^{\prime}}^{e}+\Delta \varepsilon_{3^{\prime} 3^{\prime}}^{e}\right) \\
\Delta \sigma_{3^{\prime} 3^{\prime}}^{e}=\alpha_{1} \Delta \varepsilon_{3^{\prime} 3^{\prime}}^{e}+\alpha_{2}\left(\Delta \varepsilon_{1^{\prime} 1^{\prime}}^{e}+\Delta \varepsilon_{2^{\prime} 2^{\prime}}^{e}\right) \\
\Delta \tau=2 G \Delta \gamma^{e}
\end{array}\right. \\
& \left\{\begin{array}{l}
\alpha_{1}=k+\frac{4}{3} G \\
\alpha_{2}=k-\frac{2}{3} G
\end{array}\right.
\end{aligned}
$$


where $K$ is bulk modulus and $G$ is shear modulus.

\subsubsection{Yield Criterion for the Weak Plane}

For the model with ubiquitous joints, the yield criterion coordinate system for the weak plane of the joints is shown in Figure 5. After coordinate transformation, the shear failure envelope $\mathrm{AB}$ is expressed as $f_{\mathrm{j}}^{\mathrm{s}}=0$, the tensile failure envelope $\mathrm{BC}$ is expressed as $f_{\mathrm{j}}^{\mathrm{t}}=0$, and $f_{\mathrm{j}}^{\mathrm{s}}$ and $f_{\mathrm{j}}^{\mathrm{t}}$ are expressed as:

$$
\left\{\begin{array}{l}
f_{\mathrm{j}}^{\mathrm{s}}=\tau+\sigma_{3^{\prime} 3^{\prime}} \tan \varphi_{j}-c_{\mathrm{j}} \\
f_{\mathrm{j}}^{\mathrm{t}}=\sigma_{3^{\prime} 3^{\prime}}-c_{\mathrm{j}}^{\mathrm{t}}
\end{array}\right.
$$

where $\varphi_{\mathrm{j}}$ is the cohesion of the joints and $c_{\mathrm{j}}^{\mathrm{t}}$ is the tensile strength of the joints.

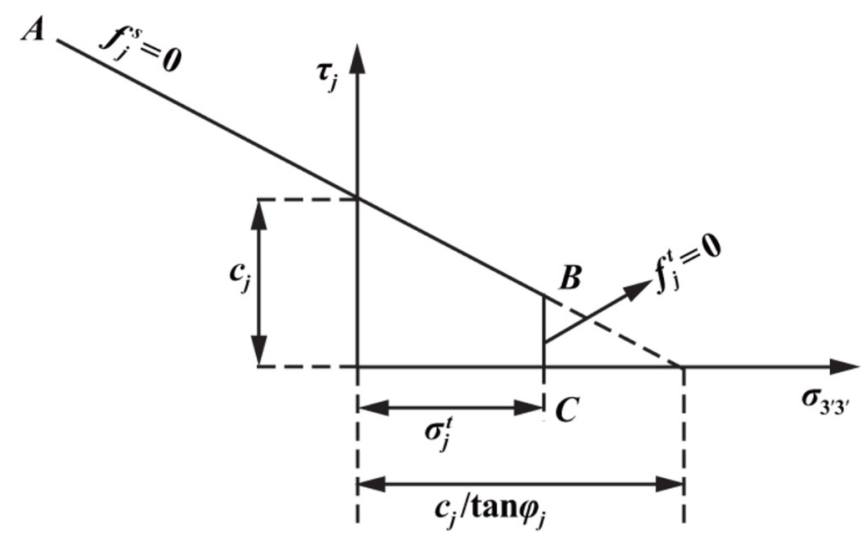

Figure 5. Weak plane failure criterion.

\subsection{Mechanical Parameters of Numerical Simulation}

The elastic modulus of the surrounding rock was determined on the basis of the GSI surrounding rock classification system, which is widely used in foreign engineering circles to estimate the strength and deformation parameters of tunnels and caverns. The value of GSI is determined based on the geological survey data of the field (Yuelongmen). According to the analysis of the actual situation of deformation of the field, the ratio of strength to stress was determined, and uniaxial compressive strength, internal friction angle, and cohesion levels were obtained by combining the uniaxial compression experiment of the field.

$$
\sigma_{\mathrm{c}}=\frac{2 c \cdot \cos \varphi}{1-\sin \varphi}
$$

The values of the mechanical parameters of the surrounding rock are presented in Table 1.

Table 1. Mechanical parameters of the surrounding rock.

\begin{tabular}{cccccccc}
\hline$\mu$ & $E(\mathrm{GPa})$ & $\boldsymbol{\Phi}\left(^{\circ}\right)$ & $\boldsymbol{T}(\mathbf{M P a})$ & $C(\mathbf{M P a})$ & $J_{\phi}\left(^{\circ}\right)$ & $J_{c}(\mathbf{M P a})$ & $J_{t}(\mathbf{M P a})$ \\
\hline 0.3 & 1.08 & $30^{\circ}$ & 0.1 & 1.56 & 27 & 0.1 & 0.05 \\
\hline
\end{tabular}

The parameters related to the spray mix and the steel arch in the initial support were based on an equivalent stiffness method. The tunnel design and the construction of the initial support involved an HW200 steel frame with a spacing of $1.0 \mathrm{~m}$. The elastic modulus of the steel frame is E2 = $200 \mathrm{GPa}$, and the elastic modulus of the C30 shotcrete according to China's Railway Tunnel Design Code (TB10003-2016) [17] is 25 GPa. A diagram of the initial support calculation is shown in Figure 6. 


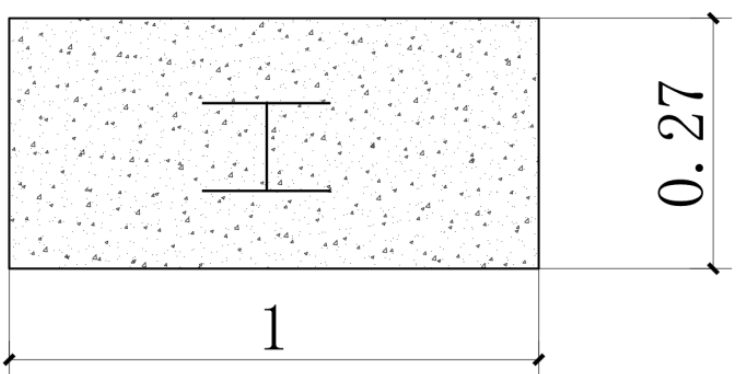

Figure 6. Diagram of the initial support calculation.

The internal friction angle of concrete is $\varphi=32-38^{\circ}$, and the compromise is $\varphi=35^{\circ}$.

According to China's Railway Tunnel Design Code (TB10003-2016) and considering the increase in the compressive strength of the section of steel frame in the initial support, the cohesion of the initial support was calculated as $\mathrm{C}=9.37 \mathrm{MPa}$. The values of the mechanical parameters of the support obtained above are presented in Table 2.

Table 2. Mechanical parameters of the support.

\begin{tabular}{cccc}
\hline$\mu$ & $E(\mathrm{GPa})$ & $\boldsymbol{\Phi}\left(^{\circ}\right)$ & $C$ \\
\hline 0.2 & 21 & 35 & 9.37 \\
\hline
\end{tabular}

\section{Engineering Application}

The modeled section of the tunnel was a single cavern in the right line of the Yuelongmen Tunnel with a height of $11 \mathrm{~m}$, a span of $9.5 \mathrm{~m}$, and a support thickness of $0.3 \mathrm{~m}$. The size of the model was $100 \mathrm{~m} \times 100 \mathrm{~m} \times 80 \mathrm{~m}$. Since the penetration direction of section YD2K100+560-YD2K100+630 perpendicular to the direction of the laminae, the angle was $80^{\circ}$, and the direction of the laminae was considered; thus, a set of laminae with an inclination angle of $80^{\circ}$ and a strike of $70^{\circ}$ was set in the numerical simulation model. The overall model and tunnel cross-section are shown in Figure 7.

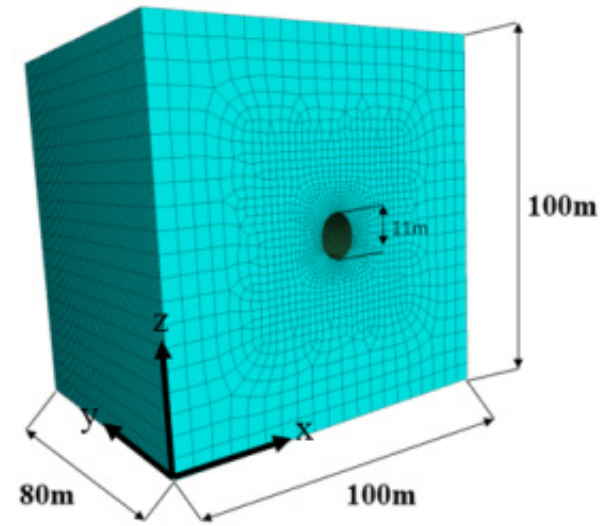

(a)

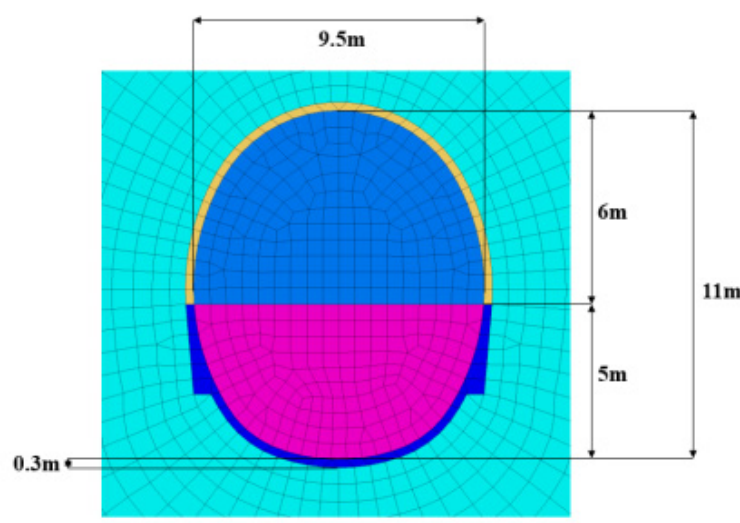

(b)

Figure 7. Diagrams showing the overall model and the tunnel section: (a) model size; (b) tunnel cross-section size.

\subsection{Comparison of Measurements and Simulation Results}

In the Yuelongmen Tunnel, right tunnel \#58 and penetration working face \#59 are located in the YD2K100+600, and this section crosses the bedding plane of the rock with a cascade dip of $80^{\circ}$. The excavation of the two stages at the site is shown in Figure 8. 


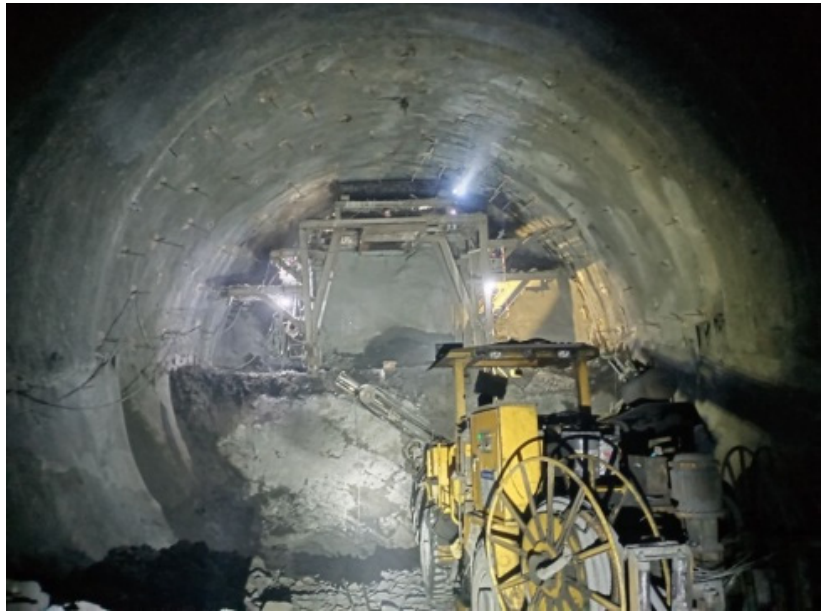

(a)

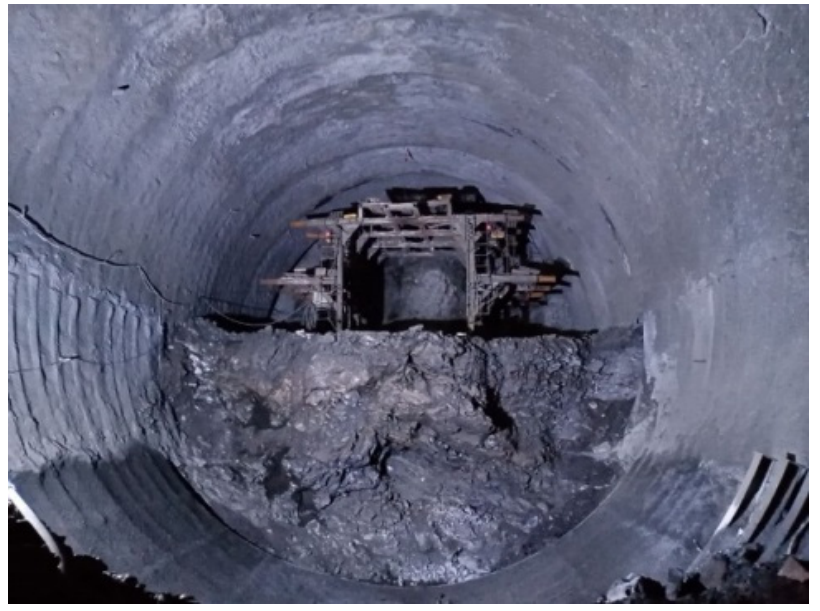

(b)

Figure 8. Photos of two stages of the excavation at the site: (a) \#58 right tunnel working face; (b) \#59 right tunnel working face.

In the numerical simulation, the position of the penetration working face was set as $\mathrm{y}=0 \mathrm{~m}$ in the section. The section deformation data was obtained from the exit side of the bottom bench, i.e., $y=3 \mathrm{~m}$ (construction entrance side) and $\mathrm{y}=-3 \mathrm{~m}$ (construction exit side). The schematic diagram of the simulated excavation is shown in Figure 9.

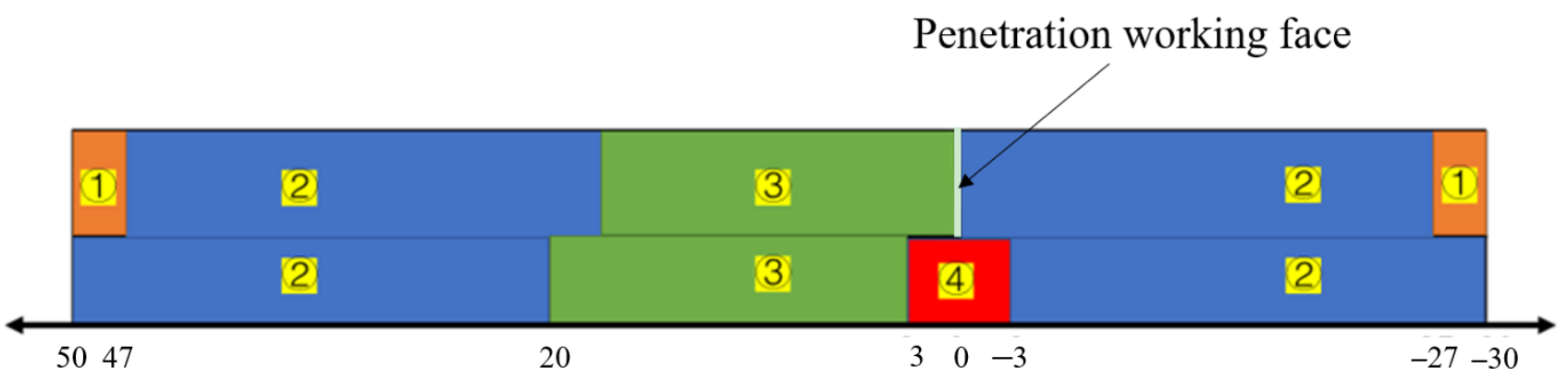

Figure 9. Schematic diagram of simulated excavation sequence.

(1): Excavation of $50 \mathrm{~m}$ to $47 \mathrm{~m}$ and $-30 \mathrm{~m}$ to $-27 \mathrm{~m}$ on the upper bench, supporting the previous step after each advance;

(2): Excavation of $47 \mathrm{~m}$ to $17 \mathrm{~m}$ and $-27 \mathrm{~m}$ to $0 \mathrm{~m}$ on the upper bench; excavation of $50 \mathrm{~m}$ to $20 \mathrm{~m}$ and $-30 \mathrm{~m}$ to $-3 \mathrm{~m}$ on the bottom bench, supporting the previous step after each advance;

(3): Excavation of $17 \mathrm{~m}$ to $0 \mathrm{~m}$ on the upper bench and $20 \mathrm{~m}$ to $3 \mathrm{~m}$ on the bottom bench, supporting the previous step after each advance. At this time, the final penetration of the working face for the upper bench was reached;

(4): Excavation of $3 \mathrm{~m}$ to $-3 \mathrm{~m}$ of the bottom bench; the final penetration of the working face for the bottom bench was reached. At this point, the tunnel was fully penetrated and the construction was completed. The actual arrangement of the construction monitoring points is shown in Figure 10. Point a in Figure 10 is used to monitor the settlement of tunnel vault, and survey lines $\mathrm{S} 1$ and $\mathrm{S} 2$ are used to monitor the convergence of two sides of the tunnel.

The analysis of the tunnel deformation near the penetration working face revealed that at mileage YD2K100+595, the accumulated settlement of the vault was $9.61 \mathrm{~cm}$, the horizontal convergence of measurement line $S 1$ was $9.62 \mathrm{~cm}$, and the horizontal convergence of measurement line S2 was $7.18 \mathrm{~cm}$. At mileage YD2K100+605, the accumulated settlement of the vault was $10.5 \mathrm{~cm}$, the horizontal convergence of measurement line S1 
was $9.14 \mathrm{~cm}$, and the horizontal convergence of measurement line S2 was $8.84 \mathrm{~cm}$. The field monitoring results were compared with the numerical simulation results (Figure 11).

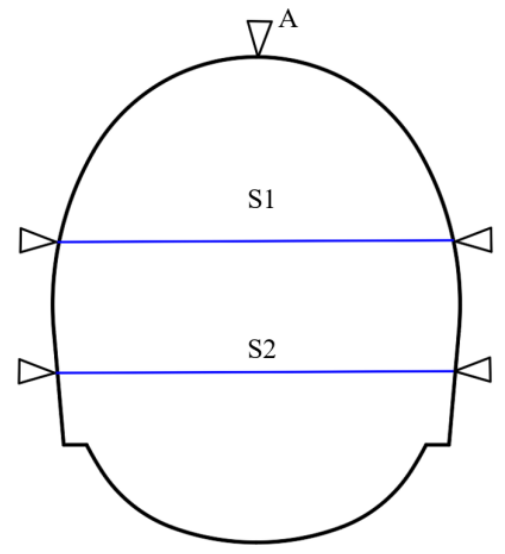

Figure 10. Field monitoring schematic.

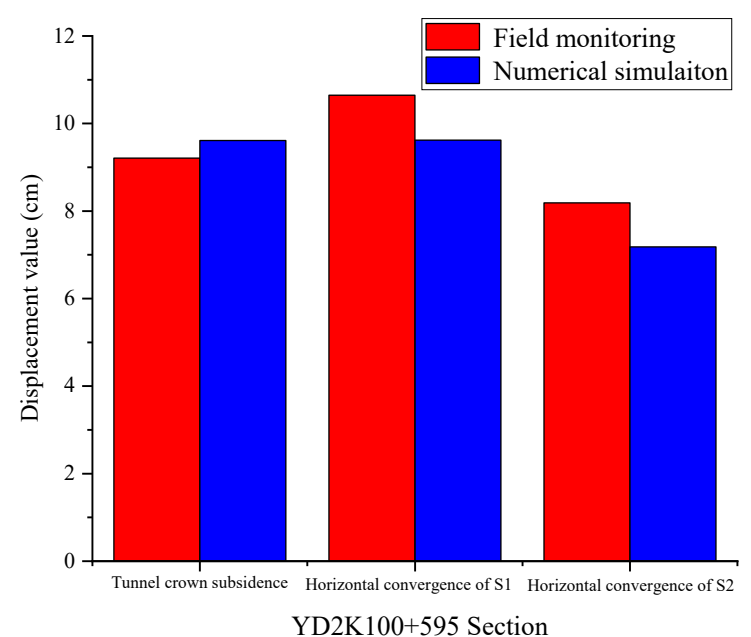

(a)

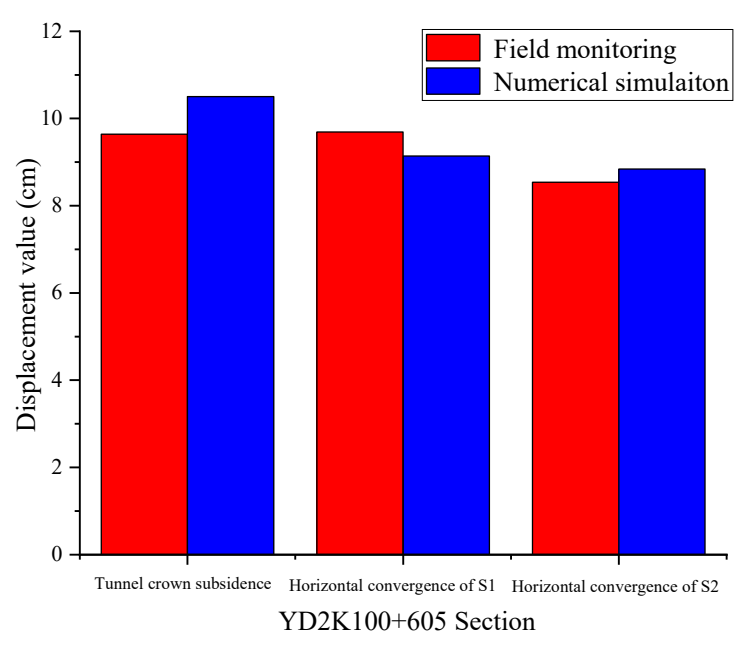

(b)

Figure 11. Comparison of the field monitoring results and the numerical simulation results: (a) tunnel cross-section YD2K100+595; (b) tunnel cross-section YD2K100+605.

As shown in Figure 11, the difference between the measured value and the simulated value of the vault settlement of the right tunnel at YD2K100+595 was 5.5\%. The difference between the measured value and the simulated value of the accumulated deformation in the horizontal direction of measurement line $\mathrm{S} 1$ was $10.8 \%$. The difference between the measured value and the simulated value of the accumulated deformation in the horizontal direction of measurement line S2 was $14 \%$. The difference between the measured value and the simulated value of the vault settlement of the right tunnel at YD2K100+605 was 8.2\%. The difference between the measured value and the simulated value of the accumulated deformation in the horizontal direction of measurement line S1 was $6 \%$. The difference between the measured value and the simulated value of the accumulated deformation in the horizontal direction of measurement line S2 was 3.4\%. By comparing the numerical simulation results with the field monitoring data, the model fitting error of the horizontal convergence between the vault settlement and the construction entrance side of the tunnel was mainly negative, with a maximum error of $-1.03 \mathrm{~cm}$; the model fitting error of the horizontal convergence between the construction exit side was positive, with a maximum error of $0.86 \mathrm{~cm}$. The difference between the measured field deformation value and the 
simulated value was small, so it is feasible to simulate tunnel excavation in layered rock using the ubiquitous joint model [18-21].

\subsection{Comparison of Measurements and Simulation Results}

Based on the comparison between the actual measured deformation values and the simulated values presented in the last section, the excavation of bedding planes with different bedding inclination angles $\left(0^{\circ}, 30^{\circ}, 60^{\circ}\right.$, and $\left.90^{\circ}\right)$ was carried out in a direction perpendicular to the direction of the tunneling. A schematic diagram of the bedding excavation is shown in Table 3.

Table 3. Schematic diagram of the tunnel excavation.

\begin{tabular}{|c|c|c|}
\hline Dip Angle & \multicolumn{2}{|c|}{ Ways of Penetration } \\
\hline $0^{\circ}$ & Through excavation side & Stopping excavation side \\
\hline $30^{\circ}$ & \multicolumn{2}{|c|}{ Through excavation side } \\
\hline $60^{\circ}$ & \multicolumn{2}{|c|}{ 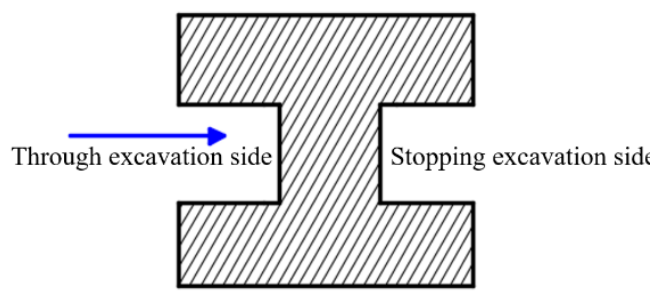 } \\
\hline $90^{\circ}$ & Through excavation side & Stopping excavation side \\
\hline
\end{tabular}

When the tunnel section was transfixed at the monitored points in both the entrance side and the exit side $(y=3 \mathrm{~m}, \mathrm{y}=-3 \mathrm{~m})$, the cumulative vault settlement was determined. The simulation results are shown in Table 4. 
Table 4. Cumulative vault settlement from the cross-section of the tunnel under the influence of different inclination angles.

\begin{tabular}{ccccc}
\hline \multirow{2}{*}{ Dip Angle } & \multicolumn{3}{c}{ Settlement of Vault $\mathbf{( c m )}$} \\
\cline { 2 - 5 } & $\begin{array}{c}\text { Through Construction Side } \\
(\mathbf{y}=\mathbf{3} \mathbf{~ m})\end{array}$ & $\begin{array}{c}\text { Stopping Construction } \\
\text { Side } \mathbf{( y = - 3 ~} \mathbf{~ m})\end{array}$ & Difference & Relative Difference \\
\hline $0^{\circ}$ & 16.5 & 26.7 & 10.2 & $61.82 \%$ \\
$30^{\circ}$ & 9.82 & 19.5 & 9.68 & $98.57 \%$ \\
$60^{\circ}$ & 7.54 & 13.3 & 5.76 & $76.39 \%$ \\
$90^{\circ}$ & 7.92 & 13.6 & 5.68 & $71.72 \%$ \\
\hline
\end{tabular}

Table 4 shows the following results: (1) the excavation on the construction entrance side resulted in significant disturbance on construction exit side. The disturbance initially increased and then decreased as the bedding angle increased, and the peak value appeared in the case of a gentle dip (about $30^{\circ}$ ). Therefore, for tunnel construction in surrounding rock with gently dipping bedding, it is necessary to strengthen the control measures for surrounding rock deformation. (2) Through comparison of the final cumulative settlement percentage of the vault on both the construction entrance side and exit side, we found that, when adopting the join-through construction scheme, the temporary support of the construction exit side should be strengthened to ensure the deformation stability of the surrounding rock mass.

4.3. Comparative Analysis of the Tunnel Excavation of CIS and Inverse Layers in Gently Inclined Surrounding Rocks

It can be seen from Table 4 that the disturbance from the construction entrance side to the construction exit side of the gently inclined rock strata $\left(0-30^{\circ}\right)$ increased with the increase of the bedding dip angle, and the influence range of excavation in both the CIS layer $\left(-30^{\circ}\right)$ and inverse layer $\left(30^{\circ}\right)$ was investigated when the direction of the slowly inclined bedding plane was perpendicular to the tunnel boring direction. Table 5 presents a schematic diagram of the different excavation directions (CIS and inverse).

Table 5. Schematic diagram of through excavation cis-layer and inverse layer.

Dip Angle

Figure 12 shows the schematic diagram of excavation from $5 \mathrm{~m}$ rock pillars left on the construction entrance side to tunnel penetration. 


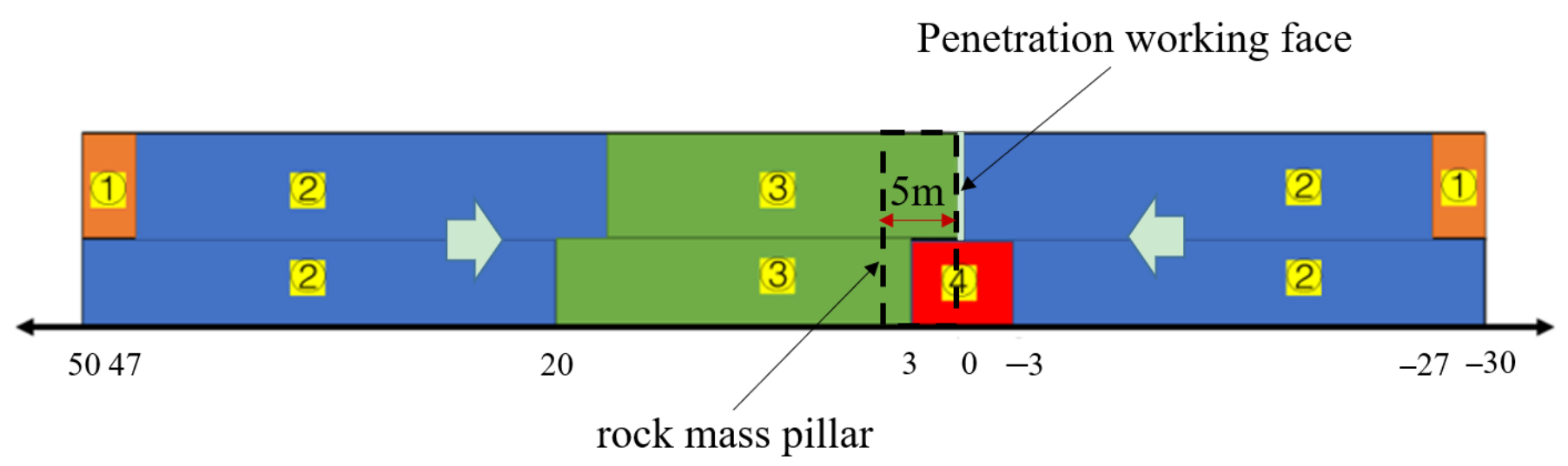

Figure 12. Schematic diagram of the excavation from $5 \mathrm{~m}$ rock pillars left on the construction entrance side to tunnel penetration.

Figure 13 shows the cumulative settlement of the tunnel vault when the rock mass pillar was either retained or excavated. The rock mass pillar was $5 \mathrm{~m}$, which is about 0.5 times the tunnel span.

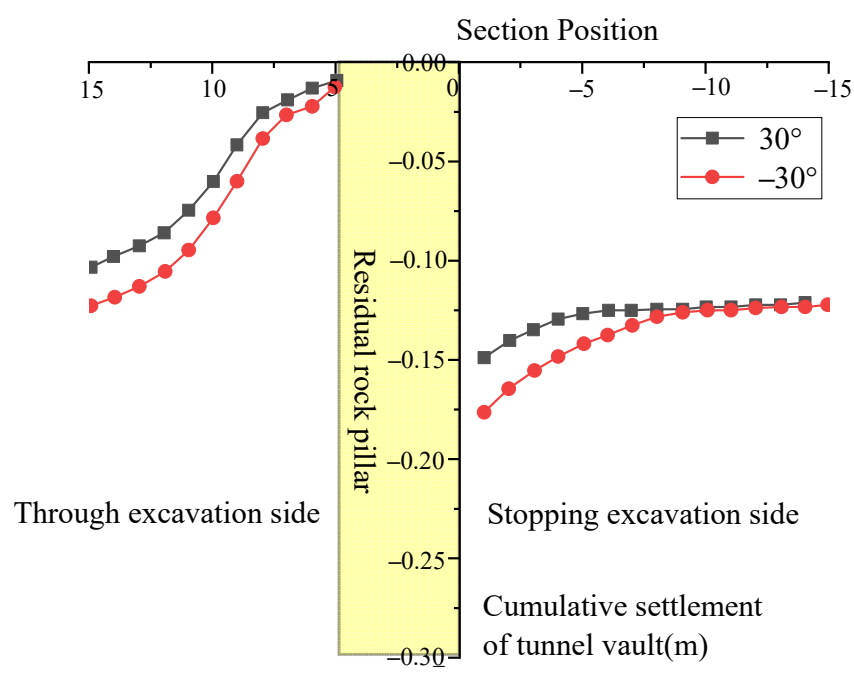

(a)

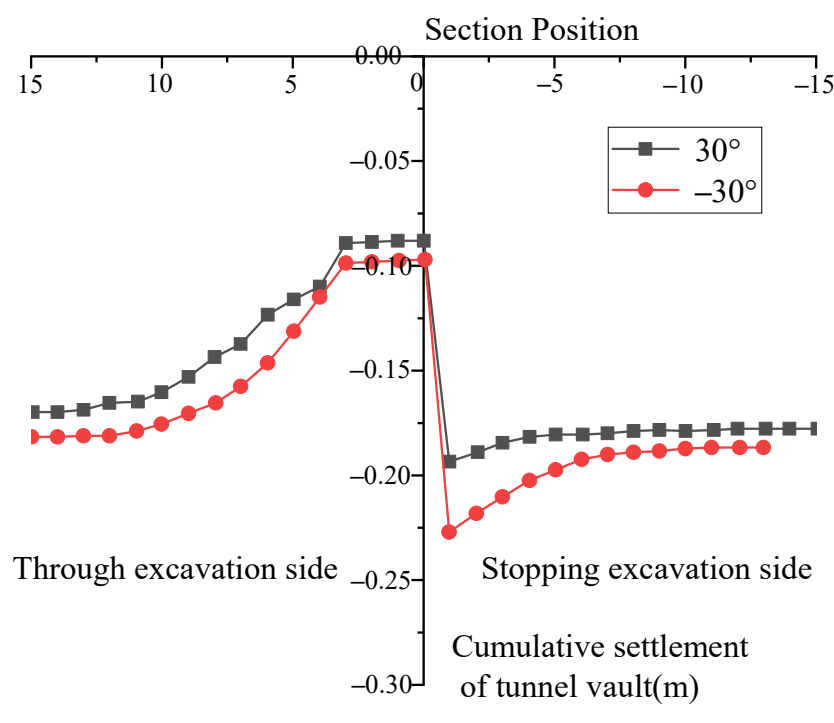

(b)

Figure 13. $Y=50 \mathrm{~m}$, cumulative vault settlement of the tunnel: (a) Retained rock mass pillar and (b) excavated rock mass pillar.

As shown in Figure 13, (1) for the settlement of the vault, the minimum accumulated deformation point was located on the construction entrance face, and the maximum accumulated deformation point was located $1 \mathrm{~m}$ away from the construction entrance face in the direction of the construction exit face. (2) When the dip angle of the bedding plane was $30^{\circ}$, in the case of an inverse layer, the cumulative deformation outside the hole diameter of the construction exit side, which was 0.5 times that of the construction entrance side, was essentially the same; that is, the influence range of the construction entrance side on the construction exit side was about 0.5 times the hole diameter. (3) When the dip angle of the bedding plane was $-30^{\circ}$, in the case of layering, the cumulative deformation outside of the hole diameter, which was one time the hole diameter from the construction exit side to the construction entrance side, was essentially the same; that is, the influence range of the construction entrance side on the construction exit side was about one time the hole diameter. (4) By comparing the cumulative settlement curves for a vault that is 0.5 times the tunnel diameter ( $5 \mathrm{~m}$ rock pillars) through the upper bench and that of a tunnel excavated 
completely penetrated, it was found that the deformation of the exit side with rock pillars retained during the tunneling was reduced by $20-25 \%$.

Figure 14 shows the cumulative uplift of the tunnel invert when the rock mass pillar was retained or excavated. The rock mass pillar was $5 \mathrm{~m}$, which is about 0.5 times the tunnel span.

As shown in Figure 14, (1) for uplift of the tunnel invert, the minimum accumulated deformation point was located on the construction entrance face, and the maximum accumulated deformation point was located $1 \mathrm{~m}$ away from the construction entrance face in the direction of the construction exit face. (2) When the dip angle of the bedding plane was $30^{\circ}$, in the case of an inverse layer, the cumulative deformation outside of the hole diameter on the construction exit side, which was one time the hole diameter of the construction entrance side, was essentially the same; that is, the influence range of the construction entrance side on the construction exit side was about one times the hole diameter. (3) When the dip angle of the bedding plane was $-30^{\circ}$, the cumulative deformation outside the hole diameter on the construction exit side was 0.5 times that of the construction entrance side and was essentially the same; that is, the impact of the construction entrance side on the construction exit side was about 0.5 times the hole diameter. (4) By comparing the cumulative uplift curve of the tunnel invert, we found that when the upper bench was connected by a span 0.5 times the tunnel diameter ( $5 \mathrm{~m}$ rock pillars) and the tunnel was completely connected, the deformation of the tunnel invert with rock pillars was 30-33\% lower than that without rock pillars.

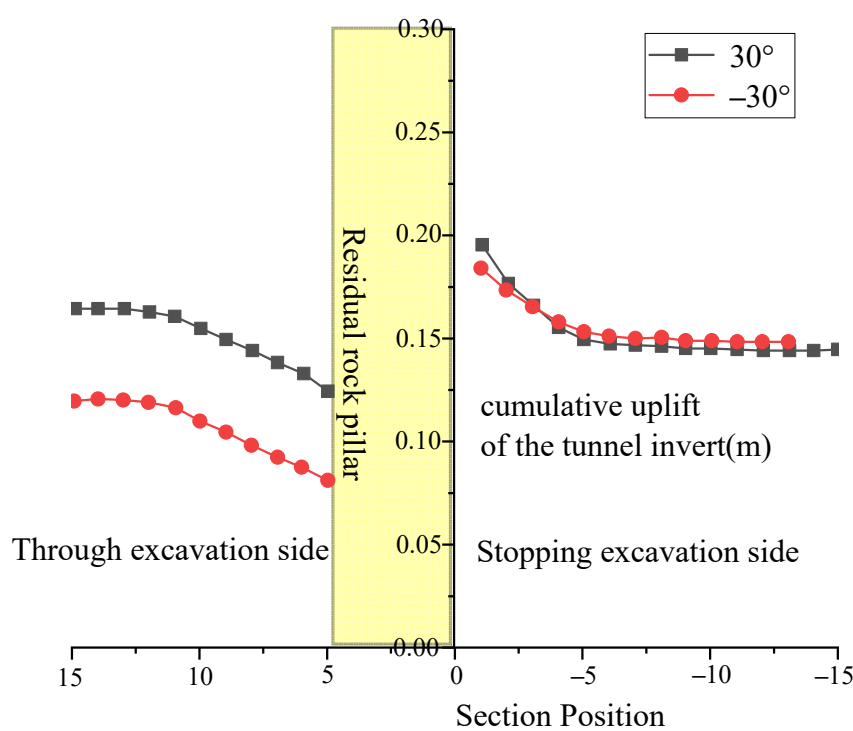

(a)

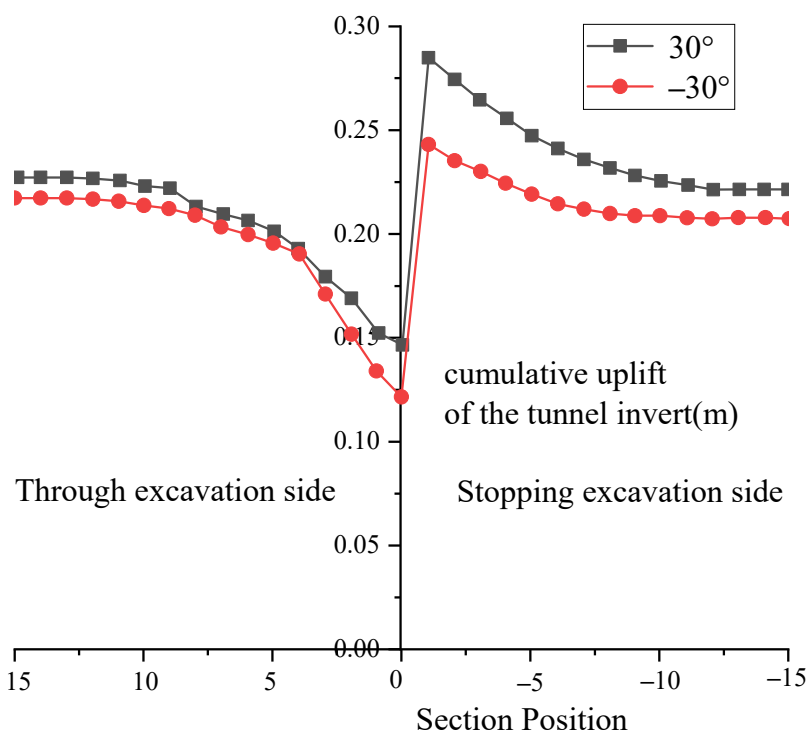

(b)

Figure 14. $Y=50 \mathrm{~m}$, cumulative uplift of the bottom of the tunnel. (a) Retained rock mass pillar and (b) excavated rock mass pillar.

Through comprehensive comparison of Figures 13 and 14, the following conclusions were obtained: (1) From the cumulative settlement of the vault when the upper bench was 0.5 times the diameter of the tunnel and the tunnel was complete, the degree of disturbance to the construction exit side caused by the excavation of the construction entrance side was very significant, which also indicated that the temporary support on the construction exit side should be strengthened when a joint-through construction scheme is adopted. (2) The final cumulative settlement of the vault was about $2-3 \mathrm{~cm}$ smaller than that of the tunnel with pillars and 0.5 times the tunnel diameter from the upper bench. The final cumulative value of the uplift of the tunnel invert was about $5-6 \mathrm{~cm}$ smaller. The magnitude of the 
deformation of the uplift of the tunnel invert was more affected by the excavation entrance than the settlement of the vault during the hole-making process.

\section{Conclusions}

(1) For a layered rock mass, three-dimensional numerical simulation using a ubiquitous joint model was conducted, and the simulation results were compared with the actual two-stage excavation of the Yuelongmen Tunnel. The comparison of the measured field section deformation data with the numerical simulation results revealed that a ubiquitous joint model can be used to simulate and analyze a layered rock mass.

(2) Due to the existence of the bedding plane, the construction entrance side has different disturbance effects on the construction exit side under different laminar dip angles. Based on the numerical simulation analysis, the construction entrance side of the gently inclined layered rock exerted more disturbance on the construction exit side.

(3) In layered rock tunnels buttressed through construction, the CIS layer direction should be preferentially selected. Moreover, the reasonable width of rock mass pillars should be further studied during tunnelling in the future.

Author Contributions: Conceptualization, X.W. and J.L.; methodology, Z.G.; software, Z.G.; investigation, X.W.; resources, J.L.; data curation Z.G.; writing—original draft preparation, Z.G.; writingreview and editing, X.W. and J.L.; visualization, K.L.; supervision, J.L. and X.W. All authors have read and agreed to the published version of the manuscript.

Funding: This research received no external funding.

Institutional Review Board Statement: Not applicable.

Informed Consent Statement: Not applicable.

Data Availability Statement: Not applicable.

Acknowledgments: The author would like to thank all the anonymous reviewers for their meticulous comments and helpful suggestions.

Conflicts of Interest: The authors declare no conflict of interest.

\section{References}

1. Luo, Y.; Chen, J.; Deng, X. Mechanical Model Calculations of Tunnel Roof with Horizontal Stratified Rock Mass Tunneling Considering the Interlayer Cohesion. China J. Highw. Transp. 2018, 31, 230-237. (In Chinese)

2. Tao, Z.; Luo, S.; He, M. Analysis of Deformation Law and Creep Characteristics of Carbonaceous Slate in Highway Tunnel. J. China Univ. Min. Technol. 2020, 49, 898-906. (In Chinese)

3. Wu, Y.; Tan, Z.; Li, S. Experimental Study on the Basic Characteristics of Tunnel in Squeezing Surrounding Rock with Large Deformation. China Civ. Eng. J. 2015, 48, 398-402. (In Chinese)

4. Lekhnitskii, S.G. Theory of Elasticity of an Anisotropic Elastic Body. Phys. Today 1964, 17, 84. [CrossRef]

5. Du, S.G.; Du, K.Q. Scale effect on the anisotropy characteristics of rock joint roughness. Q. J. Eng. Geol. Hydrogeol. 2021, 54, qjegh2020-066. [CrossRef]

6. Ge, Z.; Pan, S.; Liu, J. Estimation of Brittleness and Anisotropy Parameters in Transversely Isotropic Media With Vertical Axis of Symmetry. IEEE Trans. Geosci. Remote Sens. 2021, 60, 1-9. [CrossRef]

7. Huang, H.; Yu, Y.; Yang, C. Research on the Deformation Regularity and Treatment Measures of Tunnel Floor Heave in Gently Inclined Layered Surrounding Rock. J. Railw. Eng. Soc. 2021, 38, 72-78.

8. Sui, J.; Ren, F.; Cao, J. Numerical Analysis for the Caving Characteristics of Rock Mass with Inclined Joints in Caving Mining. Adv. Civ. Eng. 2021, 2021, 9917744. [CrossRef]

9. Tan, Z.; Li, S.; Yang, Y. Large Deformation Characteristics and Controlling Measures of Steeply Inclined and Layered Soft Rock of Tunnels in Plate Suture Zones. J. Eng. Fail. Analysis 2022, 131, 105831. [CrossRef]

10. Wang, M.; Tan, Z. The construct technology of tunnel and underground engineering in China. Strateg. Study CAE 2010, 12, 4-10. (In Chinese)

11. Wen, J. Study on Deformation Features and Control Measures of 3\# Inclined Shaft in Yuelongmen Tunnel of Chenglan Railway; Chengdu University of Technology: Chengdu, China, 2017; pp. 9-11.

12. Zhang, C. The Influence of Bedding Plane on Opposite Through Construction Safety of Long Tunnel; Beijing Jiaotong University: Beijing, China, 2021; pp. 20-21. 
13. Zhang, Q.; Jiang, A.; Wu, H. Research on Optimization of Tunnel Cyclic Advance Rate Based on Ubiquitous Joint Model. Mod. Tunn. Technol. 2020, 57, 70-77. (In Chinese)

14. Luo, F.; Zhou, X. Analysis of Influence Factors on the Stability of Bedding Slope Based on Joint Model. Railw. Stand. Des. 2017, 61, 141-146. (In Chinese)

15. Wang, Y.; Zhang, Y.; Feng, X. Model Test and Numerical Simulation of Surrounding Rock Stability of Chambers with Different Inclination Angles. Sci. Technol. Eng. 2019, 19, 281-287. (In Chinese)

16. Zhao, Y.; Yang, T. Stability Analysis of Deep Buried Tunnel based on Ubiquitous-joint. Mine Met. Mine 2016, 45, 36-41. (In Chinese)

17. China's Railway Tunnel Design Code (TB10003-2016); China Railway Press: Beijing, China, 2017.

18. Sainsbury, B.L.; Sainsbury, D.P. Practical Use of the Ubiquitous-Joint Constitutive Model for the Simulation of Anisotropic Rock Masses. Rock Mech. Rock Eng. 2017, 50, 1507-1528. [CrossRef]

19. Song, D.; Huang, J.; Liu, X. Dynamic Response of Layered Rock Slopes under Earthquakes. J. Hunan Univ. Nat. Sci. 2021, 48, 113-120.

20. Sainsbury, D.P.; Sainsbury, B.L.; Limited, C.G. Three-Dimensional Analysis of Pit Slope Stability in Anisotropic Rock Masses. In Proceedings of the Slope Stability 2013, Brisbane, Australia, 1 January 2013.

21. Chang, L.S.; Chen, Y.N.; Tao, D.H. Numerical analysis of layered rock slop based on FLAC Ubiquitous-Joint model. China Min. Mag. 2013, 22, 77-80. 